\title{
Prospective study of health related quality of life before and after coronary artery bypass grafting: outcome at five years
}

\author{
N Caine, L D Sharples, J Wallwork
}

\begin{abstract}
Objective-To determine the long term health related quality of life of coronary artery bypass graft patients, to look at changes between one and five years after surgery, and to examine the ability of preoperative variables to predict longer term outcome.
\end{abstract}

Design-Nottingham health profile (NHP) was used to assess patients at five years compared to results obtained at one year. Patients-100 male patients aged $<60$ years at time of surgery; 77 had three vessel disease and 84 received three or more saphenous vein grafts.

Results-In comparing the five year results with those at one year, lower mean scores, indicating slight improvements, were seen in the NHP dimensions of pain, sleep, social isolation, and emotional reactions, whereas signs of deterioration were noted in the physical mobility and energy scores. Chest pain was experienced by 34 of 84 patients at five years compared with 17 of 89 patients at one year. The proportion of patients who were unrestricted in their activities ranged from $61-70 \%$ at five years compared with $82-88 \%$ at one year. Absence of dyspnoea before surgery, indicating relatively good left ventricular function, was a predictor of good outcome at both one and five years.

Conclusions-Evidence of deterioration in physical function is compatible with expected decline in graft patency; specific rather than generic measures were most sensitive to this change.

(Heart 1999;81:347-351)

Keywords: quality of life; coronary artery bypass graft; Nottingham health profile

Papworth Hospital NHS Trust, Papworth

Everard,

Cambridgeshire

CB3 8RE, UK

N Caine

J Wallwork

MRC Biostatistics

Unit, Institute of

Public Health,

Cambridge, UK

L D Sharples

Correspondence to: Ms Caine.

Accepted for publication 4 December 1998 symptoms, and activity at three months and one year after CABG surgery, compared to before surgery. Predictors of return to work and to unrestricted home activity, by one year after surgery, were working preoperatively, the length of time waiting for surgery, and the absence of breathlessness before operation. This paper reports on the changes between one and five years after surgery together with an analysis of any preoperative factors still influencing outcome at five years.

\section{Patients and methods}

The study population of 100 male patients had a mean (SD) age at time of surgery of 51 (6) years (range 37-59 years); 77 patients had three vessel disease and 84 received three or more bypass grafts. Bypass surgery was performed using the saphenous vein graft; only three patients received an internal mammary artery bypass graft in addition to the vein grafts. Emergency cases were excluded because of the need to establish baseline measures of health related quality of life before surgery. Three of the 100 patients received repeat graft surgery within five years of the original operation.

The questionnaires completed by patients were the Nottingham health profile (NHP), ${ }^{2}$ which is a generic measure of health status, and a study questionnaire containing sections on symptoms, working life, home, leisure, and social and sexual activities.

The NHP is in two parts. Part I contains 38 questions in the six dimensions of physical mobility, pain, energy, sleep, social isolation, and emotional reactions. From the yes/no replies, a score from 0 to 100 is calculated for each dimension, with higher scores indicating higher levels of dysfunction or distress. In part II of the NHP, patients indicate whether seven areas of daily living are affected by their state of health: work, home life, social life, home relationships, sex life, interests/hobbies, and holidays.

The study questionnaire contains sections on working life, symptoms, and activity. Patients indicated frequency of symptoms on a scale from "never" through "occasionally", "some of the time", "most of the time" to "always". To assess the level of exertion at which problems occurred, patients with symptoms completed a scale from "rest", through "walking slowly", "walking normally", "climbing stairs", "running", to "heavy lifting". In measuring activity restrictions, patients rated the degree of restriction, caused by their health, on a scale from "no restriction" through "limited", "severely limited" to "no activity" for relevant activities.

STATISTICAL ANALYSIS

NHP part I scales are summarised using mean scores for comparisons with other studies and 


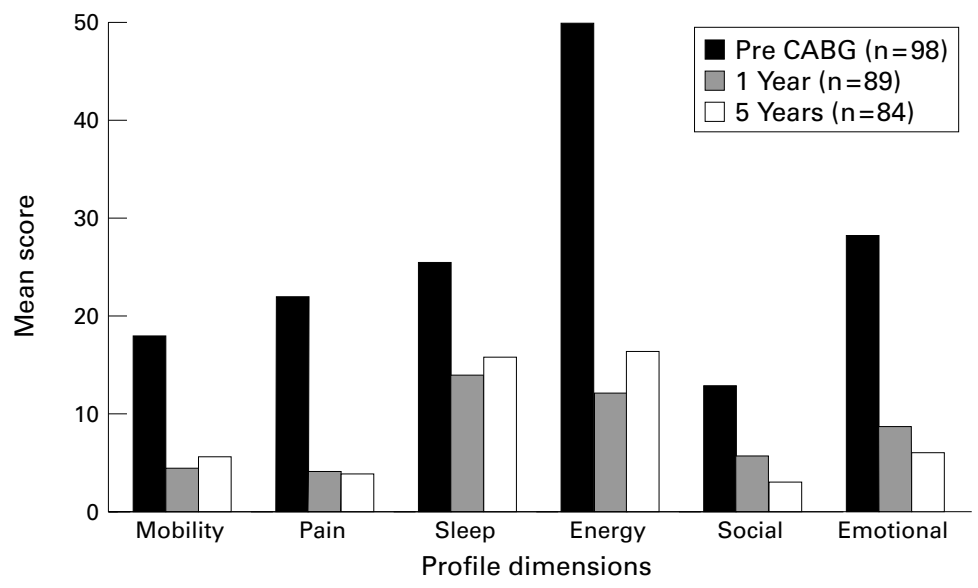

Figure 1 Mean scores from part I of the NHP, pre CABG surgery and at one and five years after surgery

Table 1 Mean scores from part I of the NHP five years after CABG compared with those in a general male population

\begin{tabular}{|c|c|c|c|c|}
\hline \multirow[b]{2}{*}{ NHP dimensions } & \multicolumn{2}{|c|}{5 years after $C A B G(n=84)$} & \multicolumn{2}{|c|}{ Normal male population * } \\
\hline & Mean & Interquartile range & Age 50-54 years & Age 55-59 years \\
\hline Physical mobility & 5.6 & $0-10.6$ & 4.1 & 3.7 \\
\hline Pain & 4.0 & $0-0.0$ & 7.1 & 2.9 \\
\hline Sleep & 15.6 & $0-20.8$ & 13.4 & 11.7 \\
\hline Energy & 16.4 & $0-24.0$ & 11.6 & 13.3 \\
\hline Social isolation & 2.9 & $0-0.0$ & 5.5 & 3.4 \\
\hline Emotional reactions & 6.0 & $0-9.8$ & 10.6 & 7.7 \\
\hline
\end{tabular}

$\star 2173$ randomly selected men from general practice.

accepted norms. Scores are not normally distributed and changes between one and five years after surgery were assessed using Wilcoxon's signed ranks test.

Categorical responses are expressed as the number of positive responses and the corresponding percentage of those returning questionnaires. Comparisons of the number of positive responses at one and five years after surgery were performed using the McNemar test. A small number who failed to complete one or five year questionnaires were excluded from this analysis. Resulting bias was considered by checking that the percentage of positive responses remained roughly the same.

To check for convergent validity of the measures used, the associations between work, symptoms, physical problems, and activities were assessed using the $\chi^{2}$ test for contingency tables. Associations between NHP part I scores

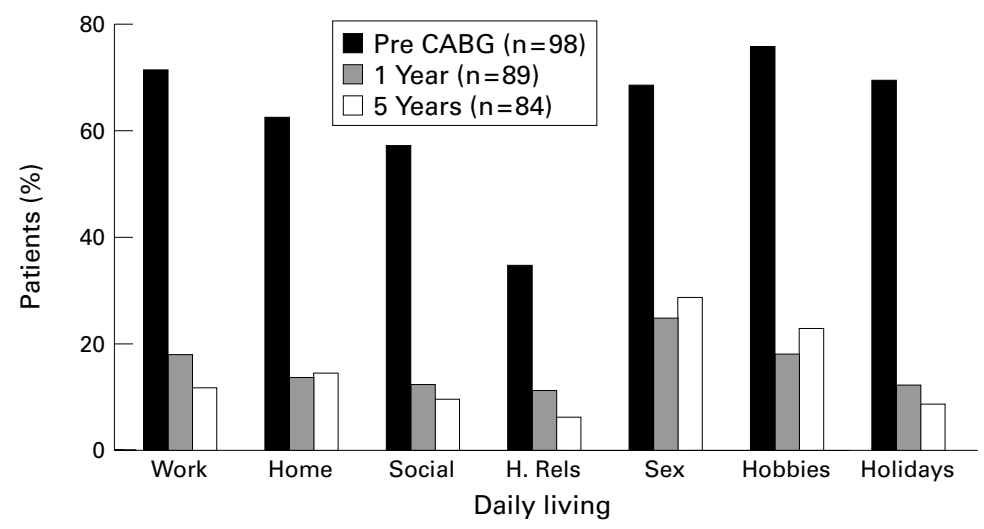

Figure 2 Part II of the NHP-percentage of patients experiencing problems in seven areas of daily living, pre CABG and at one and five years after surgery. H. Rels, home relations. and symptoms and activities were assessed using the Mann-Whitney U test.

\section{Results}

At five years following surgery, 84 of the 100 patients returned questionnaires. Of the missing 16, four were deceased, three were not traced, and nine failed to return questionnaires. These figures compare with 98 respondents before surgery, 91 at three months after surgery, and 89 at one year following surgery.

\section{NOTTINGHAM HEALTH PROFILE}

From part I of the NHP, mean scores at five years were compared with those before surgery and at one year following CABG (fig 1), with lower scores indicating better health status. In comparing the one and five year results, non-significant improvements can be seen in the dimensions of pain, sleep, social isolation, and emotional reactions, and non-significant deterioration was noted in the physical mobility and energy scores. When comparing the patients' scores at five years with those from a general population sample, ${ }^{3}$ physical mobility, energy, and sleep scores were higher (table 1).

From part II of the NHP, the percentage of patients who indicated that they were experiencing problems in daily activities, because of their current state of health, before and at one and five years after CABG surgery, are shown in fig 2 . In comparing results at one and five years following surgery, small improvements were seen in working life and social life, home relationships, and holidays. The improvement in working life did not mean that more patients were working at five years, simply that fewer patients considered their state of health either to be a problem or to be relevant to their working life. There were slight increases in the number of patients indicating problems in sex life and hobbies, and no difference between the one and five year responses in looking after the home. None of these changes were significant.

\section{STUDY QUESTIONNAIRE}

\section{Working life}

At five years after CABG surgery 54 of 84 patients $(64 \%)$ were working compared to 65 of $89(73 \%)$ patients at one year after surgery and 49 of $98(50 \%)$ before surgery. Of the 54 patients working at five years, $28(52 \%)$ were in manual and $26(48 \%)$ were in non-manual occupations. Compared with before surgery, 21 patients $(25 \%)$ were doing a different job, nine $(11 \%)$ had changed to lighter work, and four $(5 \%)$ were working fewer hours.

Of the 28 patients (33\%) not working at five years after surgery (two patients failed to indicate their work status), only four patients considered themselves fit to work, three said they were still planning to return to work, and 11 patients were retired. Thirteen patients (16\%) had worked at some time since their operation; of these, two had worked for less than six months and 11 for longer than a year. 


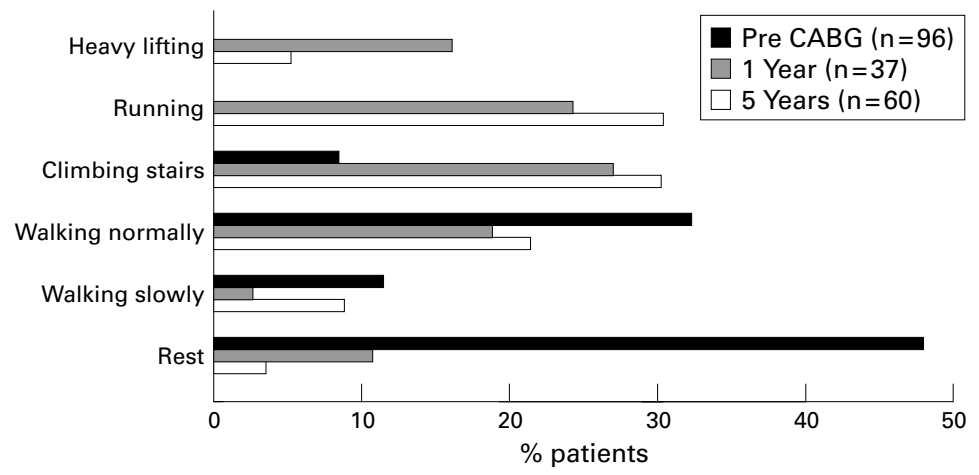

Figure 3 Level of exertion at which symptoms were experienced, pre-CABG and at one and five years after surgery

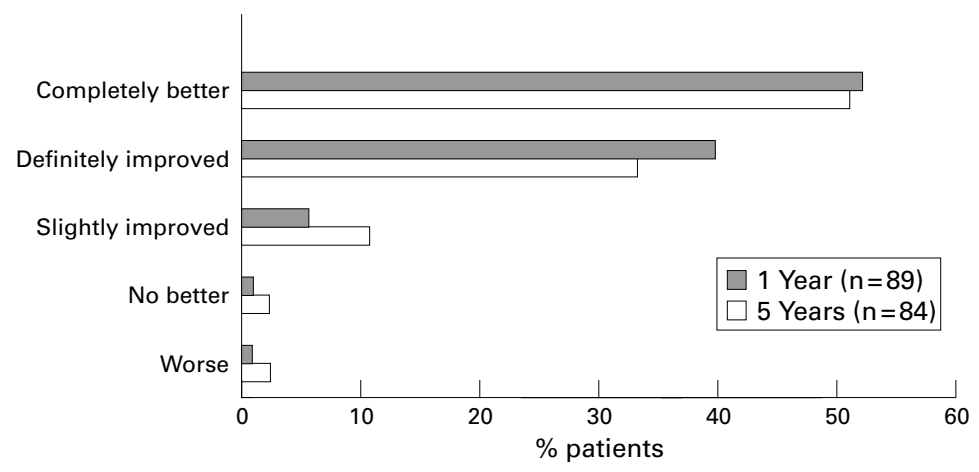

Figure 4 Patient ratings of their recovery at one and five years after CABG surgery

\section{Symptoms}

At five years after surgery, chest pain was a problem for $34(40 \%)$ patients, of whom for 22 $(65 \%)$ it occurred occasionally. Breathlessness was a problem for $50(60 \%)$ patients, the frequency being occasional or some of the time for 34 of $50(68 \%)$. This prevalence of symptoms at five years, compared with one year figures of 17 patients $(19 \%)$ with chest pain and 29 (33\%) with breathlessness, represented a significant difference $(p<0.001)$.

There was no difference in the levels of exertion which brought on symptoms at one and five years (fig 3).

Patients' assessment of outcome

Patients were asked to give a general rating of their condition after surgery compared with before surgery, on a scale from "worse" to "completely better" (fig 4). Fewer patients said they were either "completely better" or "definitely improved" at five years compared to one year; there was an increase in those who rated their condition as "slightly improved" but no increase in those who were "no better" or "worse".

\section{Activities}

The changes in home, leisure, and social activity restrictions, before surgery and at one and five years after surgery, are shown in table 2 . The number of patients completing these sections reflect the proportion of the total respondents for whom these activities were relevant to their daily lives.

At five years, the proportion of patients reporting no restrictions in home activities, hobbies/interests, and social life had declined significantly $(\mathrm{p}=0.01)$.

\section{ASSOCIATIONS BETWEEN SYMPTOMS AND ACTIVITY}

Our earlier findings relating return to work to the prevalence of breathlessness and chest pain in CABG patients at one year ${ }^{1}$ are confirmed by the figures at five years after surgery. Of those 28 patients not working at five years, 18 $(64 \%)$ had experienced chest pain and 22 (79\%) breathlessness, compared to $14(26 \%)$ and $26(48 \%)$ of the 54 patients working $(\mathrm{p}<0.01)$.

At one and five years following surgery, 18 and 19 patients respectively said that they had other physical problems or conditions which affected their physical or work activity. Again, there was a clear relation with working status; $13(46 \%)$ of the 28 non-workers at five years said they had problems compared to six $(12 \%)$ of the 54 workers $(\mathrm{p}<0.001)$.

As might be expected there was a strong relation between presence of symptoms and restrictions in home, leisure, and social activities $(\mathrm{p}<0.01)($ table 3$)$.

ASSOCIATIONS BETWEEN SYMPTOMS, ACTIVITY, AND NHP SCORES

The median scores of the "physical" dimensions of the NHP at five years after surgery (physical mobility, pain, and energy) were

Table 2 Activity restrictions before $C A B G$ and at one and five years after surgery

\begin{tabular}{|c|c|c|c|c|c|c|c|c|c|}
\hline \multirow[b]{2}{*}{ Activity scale } & \multicolumn{3}{|l|}{ Home } & \multicolumn{3}{|l|}{ Leisure } & \multicolumn{3}{|l|}{ Social } \\
\hline & $\begin{array}{l}\text { Before } \\
(n=91)\end{array}$ & $\begin{array}{l}1 \text { year } \\
(n=85)\end{array}$ & $\begin{array}{l}5 \text { years } \\
(n=78)\end{array}$ & $\begin{array}{l}\text { Before } \\
(n=84)\end{array}$ & $\begin{array}{l}1 \text { year } \\
(n=71)\end{array}$ & $\begin{array}{l}5 \text { years } \\
(n=82)\end{array}$ & $\begin{array}{l}\text { Before } \\
(n=70)\end{array}$ & $\begin{array}{l}1 \text { year } \\
(n=73)\end{array}$ & $\begin{array}{l}5 \text { years } \\
(n=81)\end{array}$ \\
\hline No restriction & $17(19)$ & $70(82)$ & $54(69)$ & $4(5)$ & $58(82)$ & $50(61)$ & $13(19)$ & $64(88)$ & $57(70)$ \\
\hline Limited & $5(6)$ & $2(2)$ & $21(27)$ & $9(11)$ & $0(0)$ & $24(29)$ & $2(3)$ & $1(1)$ & $17(21)$ \\
\hline Severely limited & $34(37)$ & $7(8)$ & $1(1)$ & $29(35)$ & $6(9)$ & $3(4)$ & $35(50)$ & $8(11)$ & $5(6)$ \\
\hline No activity & $35(39)$ & $6(7)$ & $2(3)$ & $42(50)$ & $7(10)$ & $5(6)$ & $0(29)$ & $0(0)$ & $2(3)$ \\
\hline
\end{tabular}

Values are $\mathrm{n}(\%)$.

Table 3 Associations between symptoms and activity at five years

\begin{tabular}{|c|c|c|c|c|c|c|c|c|}
\hline & \multicolumn{2}{|l|}{ Home activities } & \multicolumn{2}{|c|}{ Leisure activities } & \multicolumn{2}{|l|}{ Social activities } & \multicolumn{2}{|c|}{ Sexual activities } \\
\hline & $\begin{array}{l}\text { Not restricted } \\
(n=54)\end{array}$ & $\begin{array}{l}\text { Restricted } \\
(n=24)\end{array}$ & $\begin{array}{l}\text { Not restricted } \\
(n=50)\end{array}$ & $\begin{array}{l}\text { Restricted } \\
(n=32)\end{array}$ & $\begin{array}{l}\text { Not restricted } \\
(n=57)\end{array}$ & $\begin{array}{l}\text { Restricted } \\
(n=24)\end{array}$ & $\begin{array}{l}\text { Not restricted } \\
(n=39)\end{array}$ & $\begin{array}{l}\text { Restricted } \\
(n=45)\end{array}$ \\
\hline Chest pain & $14(26)$ & $16(67)$ & $13(26)$ & $20(63)$ & $16(28)$ & $16(67)$ & $7(18)$ & $27(60)$ \\
\hline Breathlessness & $25(46)$ & $21(88)$ & $22(44)$ & $27(84)$ & $26(46)$ & $21(88)$ & $14(36)$ & $36(80)$ \\
\hline
\end{tabular}

Values are $\mathrm{n}(\%)$. 
strongly related to both chest pain and dyspnoea, and to home, leisure, and social activities $(p<0.01)$. The lower the NHP score, in each of these dimensions, the more likely patients were to be free from symptoms and restrictions in activity. The median score for emotional reactions was significantly related to all these variables except chest pain $(p<0.01)$. The social isolation score was not significantly associated with symptoms but a lower score was strongly related to freedom from restrictions in home, leisure, and social activities $(p<0.01)$. Finally, problems with sleeping were not strongly associated with either chest pain $(p=0.07)$ or social life $(\mathrm{p}=0.07)$, but were associated with breathlessness $(p=0.02)$ and restrictions in home and leisure pursuits $(\mathrm{p}=0.005)$ (data available from the authors).

PREOPERATIVE PREDICTORS OF OUTCOME

Patients who were working before surgery were more likely to be working at both one and five years after surgery. Of the 46 patients who had worked in the six months before surgery, 33 $(72 \%)$ were working at five years after surgery compared to 21 of 36 (58\%) who had been out of work for longer than six months before surgery.

Patients who experienced dyspnoea before surgery, indicating more severely impaired left ventricular function, were more likely to be breathless and restricted in home, leisure, and social activities at both one and five years after surgery. At five years 17 of 32 patients (53\%) free from breathlessness before surgery continued to be free from this symptom after surgery, compared to 16 of 51 patients (31\%) with breathlessness before surgery $(p=0.05)$. In home activity, 26 of 29 patients (90\%) free from breathlessness before surgery were free from restrictions in home activity at five years, compared to 28 of 48 (58\%) with breathlessness before surgery $(\mathrm{p}=0.04)$. In leisure and social activities, 24 of 31 patients $(77 \%)$ and 26 of 30 patients $(87 \%)$ free from breathlessness before surgery, were free from restrictions at five years after surgery, compared to $26(52 \%)$ and $31(62 \%)$ of 50 patients with breathlessness before surgery $(\mathrm{p}=0.02)$.

\section{Discussion}

Combining a generic measure of health status with disease or condition specific scales is the increasingly accepted minimum package in measuring health related quality of life. The generic measure will enable results to be set in context with other patient groups and/or general populations, and the specific scales will provide additional information relevant to the condition and treatment under scrutiny. ${ }^{4}$ In our study, the generic NHP picked up non-significant deterioration in the dimensions of physical mobility and energy at five years compared to one year after surgery. The NHP is noted for its insensitivity to differences in health status at the healthy end of the scale, as demonstrated by the high number of zero scores after treatment. The scales for symptom frequency and activity restrictions in the study questionnaire did identify significant changes. The use of multi-item scales in which each item has several levels of frequency or severity, is a much more effective way to measure change because such a method is much more likely to differentiate partial improvement, from nil or total improvement. We found strong associations particularly between the "physical" dimension scores of the NHP and the questionnaire scales. What we can conclude from these findings is that the study questionnaire added to the sensitivity of the results against a background of strong evidence of convergent validity with the NHP.

The other main report on health related quality of life at five years after CABG surgery is the US Veterans' study in which patients were randomised to medical or surgical plus medical treatment. ${ }^{6}$ All patients included in the trial were aged less than 70 years, had unstable angina, and bypass surgery was performed using the saphenous vein graft. The prevalence of chest pain following surgery was one of the few remaining significant differences between the groups at five years after entry to the trial. Of the 155 patients in the surgery group, 85 $(55 \%)$ were free from chest pain at five years, compared to 52 of the 158 medical patients (33\%). This compares well to the $60 \%$ (50 of 84) of our patients who were free from chest pain at five years.

The evidence of deterioration in physical health related quality of life, picked up by both the NHP and the study questionnaire, makes sense considering what is known regarding the patency of the saphenous vein graft. ${ }^{7}$ It also makes sense owing to the fact that patients were four years older than at one year follow up, with consequent restrictions because of aging. In our results at one year after surgery, the preoperative variables which were major factors influencing return to work and to unrestricted home activities were: working before operation; short waiting time; absence of breathlessness; and a low NHP physical mobility score. ${ }^{1}$ Only absence of breathlessness before surgery, indicating relatively unimpaired left ventricular function, differentiated outcome at five years after surgery.

The use of the internal mammary artery is associated with excellent long term patency and improved early and late survival, with fewer myocardial infarctions and reoperations. ${ }^{9}{ }^{10}$ It is also now widely accepted that the use of aspirin started soon after surgery and continuing long term reduces the graft occlusion rate. ${ }^{11}$ What do these changes mean for the results of this study? In the absence of formal measurement, one could suppose that if these improvements have affected health related quality of life, it will have been for the better. We can therefore surmise with some confidence that the combination of using the mammary artery and longer term use of aspirin, should produce a reduction in symptom frequency and severity and further delay the need for repeat surgery, extending the "seven year glitch" described by Petch. ${ }^{12}$

It is hoped that the results from this study will provide a valuable source of reference 
when measuring health related quality of life outcomes from new developments in revascularisation, including laser and minimally invasive surgical techniques.

1 Caine N, Harrison SCW, Sharples LD, et al. Prospective study of quality of life before and after coronary artery bypass grafting. BMF 1991;302:511-16.

2 McEwen J. The Nottingham health profile: a measure of perceived health. In: Teeling-Smith G, ed. Measuring the social benefits of medicine. London: Office of Health Economics, 1985:75-84.

3 Hunt SM, McEwen J, McKenna SP. Perceived health: age and sex comparisons in the community. $f$ Epidemiol Community Health 1984;38:156-60.

4 Fletcher AE, Gore SM, Jones DR, et al. Quality of life measures in health care. II. design, analysis and interpretation. BMF 1992;305:1145-8.

5 Mayou R, Bryant B. Quality of life in cardiovascular disease. Br Heart $\mathcal{F}$ 1993;69:460-6.
6 Booth DC, Deupree RH, Hultgren HN, et al. Quality of life after bypass surgery for unstable angina. Circulation after bypass s.

7 Fitzgibbon GM, Leach AD, Kafka HP, Keon WJ. Coronary bypass graft fate: long term angiographic study. $f \mathrm{Am}$ Coll Cardiol 1991;5:1075-80

8 Lytle BW, Loop FD, Cosgrove DM, et al. Long term (5 to 12 years) serial studies of internal mammary artery and saphenous vein coronary bypass grafts. 7 Thorac Cardiovasc Surg 1985;89:248-58.

9 Loop FD, Lytle BW, Cosgrove DM, et al. Influence of the internal mammary graft on 10 year survival and other cardiac events. $N$ Engl $f$ Med $1986 ; 314: 1-6$.

10 Cameron A, Kemp Jr HG, Green GE. Bypass surgery with the internal mammary artery graft: 15 year follow up. Circulation 1986;74(suppl III):30-6.

11 Gavaghan TP, Gebski V, Baron DW. Immediate postoperative aspirin improves vein graft patency early and late after coronary artery bypass graft surgery: a placebo-controlled, randomized study. Circulation 1991;83:1526-33.

12 Petch M. Coronary bypasses 10 years on. BMf 1991;303: 661-2.

\section{IMAGES IN CARDIOLOGY}

\section{Unilateral pulmonary oedema complicating supine bicycle exercise echocardiography}
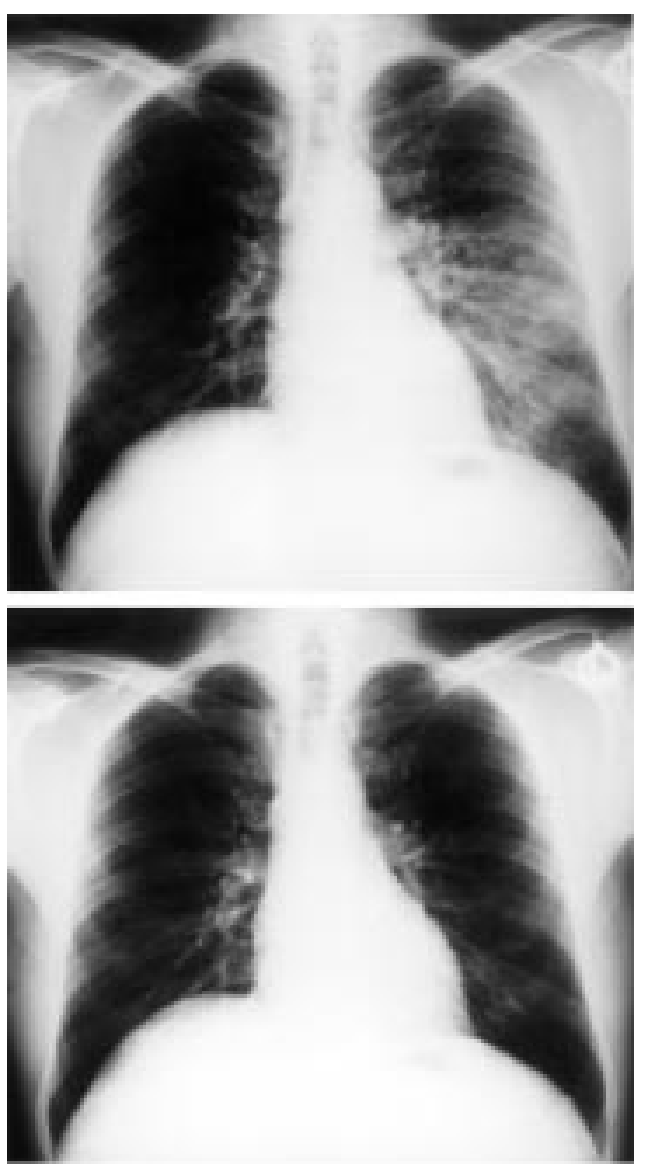

Stress echocardiography is a well established tool in modern cardiology, which increases the diagnostic accuracy of exercise ECG in regards to detection of ischaemia in patients with known or suspected coronary artery disease by $15-20 \%$. Several methods have been introduced to provoke an ischaemia, the most important of which are dynamic exercise using either treadmill or bicycle and pharmacological stimulation with dipyridamole or dobutamine. All of these modalities have a low complication rate, with severe events such as pulmonary oedema, arrhythmia, myocardial infarction or death reported in about $1-3 \%$ using the pharmacological approach. However, information regarding complications occurring when stress echocardiography is being performed with the patient in left lateral decubitus supine position is not yet available.

We encountered a 45 year old male patient who developed a unilateral pulmonary oedema immediately following dynamic, bicycle ergometer stress echocardiography. Coronary angiography detected a subtotal restenosis of the right coronary artery, which was immediately dilated, followed by the placement of a $3.0 \mathrm{~mm}$ Wiktor stent. The patient was discharged after a negative stress test up to 125 watts. He was clinically stable and asymptomatic.

H VÖLLER C DOVIFAT K SCHRÖDER 